\title{
c-Myc protein expression is not an independent prognostic predictor in cervical squamous cell carcinoma
}

\section{S.M.F. Brenna ${ }^{1}$, \\ L.C. Zeferino ${ }^{2}$, G.A. Pinto ${ }^{3}$, \\ R.A. Souza ${ }^{4}$, \\ L.A.L. Andrade ${ }^{5}$, \\ J. Vassalo $0^{5}$ \\ E.Z. Martinez ${ }^{6}$ and \\ K.J. Syrjänen ${ }^{7}$}

\author{
${ }^{1}$ Grupo de O ncologia Ginecológica, Hospital Maternidade Leonor M endes de Barros, \\ Secretaria da Saúde do Estado de São Paulo, São Paulo, SP, Brasil \\ ${ }^{2} O$ ncologia Ginecológica, ${ }^{2}$ Laboratório de Patologia Experimental, \\ Departamentos de ${ }^{4}$ Clínica M édica, ${ }^{5}$ Patologia, and ${ }^{6}$ Estatística, \\ Faculdade de Ciências M édicas, Universidade Estadual de Campinas, \\ Campinas, SP, Brasil \\ ${ }^{7}$ Unit of Cytopathology, Laboratory of Epidemiology and Biostatistics, \\ Istituto Superiore di Sanità (ISS), Rome, Italy
}

\section{Correspondence \\ S.M.F. Brenna \\ Grupo de Oncologia Ginecológica Hospital Maternidade Leonor \\ Mendes de Barros \\ Av. Celso Garcia, 2477 \\ 03015-000 São Paulo, SP \\ Brasil \\ Fax: + 55-11-6694-4925 \\ E-mail: brenna.ops@zaz.com.br}

Research supported by FAPESP (No. 98/10174-4).

Received June 28, 2001 Accepted February 27, 2002

\section{Abstract}

The c-myc protein is known to regulate the cell cycle, and its downregulation can lead to cell death by apoptosis. The role of c-myc protein as an independent prognostic determinant in cervical cancer is controversial. In the present study, a cohort of 220 Brazilian women (mean age 53.4 years) with FIGO stage I, II and III (21, 28 and 51\%, respectively) cervical squamous cell carcinomas was analyzed for c-myc protein expression using immunohistochemistry. The diseasefree survival and relapse-rate were analyzed using univariate (KaplanMeier) survival analysis for 116 women who completed the standard FIGO treatment and were followed up for 5 years. Positive c-myc staining was detected in $40 \%$ of carcinomas, $29 \%$ being grade $1,9 \%$ grade 2 , and $2 \%$ grade 3 . The distribution of positive c-myc according to FIGO stage was $19 \%$ (17 women) in stage I, $33 \%$ (29) in stage II, and $48 \%$ (43) in stage III of disease. During the 60 -month follow-up, disease-free survival in univariate (Kaplan-Meier) survival analysis (116 women) was lower for women with c-myc-positive tumors, i.e., $60.5,47.5$ and $36.6 \%$ at 12,36 , and 60 months, respectively (not significant). The present data suggest that immunohistochemical demonstration of c-myc does not possess any prognostic value independent of FIGO stage, and as such is unlikely to be a useful prognostic marker in cervical squamous cell carcinoma.

\section{Introduction}

Growth factors and products of some oncogenes are active in cell cycle regulation (1). The c-myc oncogene was one of the first to be characterized, initially discovered in Burkitt lymphoma (2). The c-myc gene is located in chromosome 8q24, has 3 exons,

\author{
Key words \\ - c-myc \\ - Oncogene \\ - Cervical cancer \\ - Prognosis
}


expression can lead to cell apoptosis (4).

Human papillomaviruses (HPV) are considered to be the single most important etiological factors of cervical squamous cell carcinoma (SCC), and, interestingly, high-risk HPV 16 sequences have been demonstrated to be integrated into the $8 \mathrm{q} 24.1$ band in these lesions. This suggests that HPV integration in the fragile sites of c-myc might be one of the potential mechanisms of HPV-induced oncogenesis (5). However, this is unlikely to be the main mechanism in cervical carcinogenesis, because the presence of HPV could allow the accumulation of mutations in the c-myc gene while compromising the guardian function of $\mathrm{p} 53$ by complexing with the HPV E6 oncoprotein (6).

The role of c-myc protein as a prognostic marker in cervical cancer is far from clear. There are studies linking c-myc expression to an unfavorable prognosis $(7,8)$, whereas other studies have failed to demonstrate such an association $(9,10)$. It is well known that major differences in the incidence rates of cervical cancer exist among different geographic areas, partly explained by the different levels of implementation of the Pap smearbased screening programs. So far, most of these prognostic studies on c-myc have been completed in developed countries, where the more effective preventive measures detect the less aggressive tumors, selecting out the most aggressive forms (11).

To circumvent this type of selection bias, the present study was carried out on Brazilian women who had not routinely undergone screening programs to further evaluate c-myc expression as a prognostic marker in cervical cancer.

\section{Material and Methods}

\section{Study design, sampling and clinical data}

The study was conducted on a cohort of 220 women diagnosed and treated for cervical carcinoma (FIGO stages Ib-III) at two clinics between 1992 and 1994, and subsequently followed up for 5 years. The patients were admitted to a) Maternity Hospital Leonor Mendes de Barros, Health State Secretariat, São Paulo, SP, Brazil, or b) to the Women's Health Care Center, the State University of Campinas (Unicamp), Campinas, SP, Brazil. The mean age of the patients was 53.4 years ( $\mathrm{SD} \pm 12.9$ years), and the range was 25 to 89 years. The primary treatment of the patients was based strictly on the FIGO stage of the disease, with several optional modes: radical surgery, radical surgery plus radiotherapy, external radiotherapy alone, external radiotherapy plus brachytherapy, and external radiotherapy plus chemotherapy. The treatment was considered to fulfil FIGO standards when completed within 120 days. FIGO stage was available for all patients, and the pertinent clinical data were collected from the patient records. Follow-up was performed by repeated physical examinations and complementary tests according to the routine follow-up protocols of cervical cancer patients at the two clinics.

The Ethics Board Committees approved the research plan and written informed consent was obtained from all patients.

\section{Histology}

Colposcopic diagnostic biopsies or operative specimens from all women were available for study. The samples were fixed in $10 \%$ neutral formalin, embedded in paraffin, and processed for $4-\mu \mathrm{m}$ thick HE-stained sections according to routine procedures. The histological diagnosis of SCC was confirmed in all cases.

\section{Immunohistochemistry of c-myc protein}

c-Myc protein expression was demonstrated in paraffin-embedded sections using conventional immunohistochemical techniques. Briefly, 4- $\mu \mathrm{m}$ sections of the tumor were deparaffinized, hydrated and endoge- 
nous peroxidase was blocked with $\mathrm{H}_{2} \mathrm{O}_{2}$. Antigen retrieval was achieved by boiling the slides in $0.1 \mathrm{mM}$ citrate buffer, $\mathrm{pH} 6.0$, in a steamer. After cooling, the sections were incubated with the monoclonal antibodies (Santa Cruz Biotechnology MX 9E10, dilution 1:80, Santa Cruz, CA, USA), overnight, at $4^{\circ} \mathrm{C}$. The reaction was detected with the streptavidin-biotin-peroxidase complex and stained with diaminobenzidine. Counterstaining was performed with Meyer's hematoxylin. Positive and negative controls consisted of simultaneously processed sections of carcinomas previously shown to be immunoreactive for c-myc. The intensity of immunostaining was scored as follows: grade $1,<20 \%$; grade $2,20-60 \%$, and grade $3,>60 \%$ of cells staining positive (see Figure 1). For statistical analysis, c-myc staining was scored as either negative or positive (c-myc + or c-myc-).

\section{Statistical analysis}

The predictive value of c-myc for diseasefree survival was estimated by univariate (Kaplan-Meier) survival analysis for 116 women who completed the standard FIGO treatment, and the survival curves for c-mycpositive and -negative tumors were compared by the Wilcoxon test, adjusted by FIGO stage. To run the multivariate (Cox model) survival analysis, the assumption of proportional hazards for c-myc strata (negative and positive) was first tested by log-minus-log plots. Because it was found to be violated, the Cox regression model was not considered appropriate for data analysis. Instead, a test based on Wilcoxon statistics pooled over strata was used to estimate the association of c-myc with disease-free survival by FIGO stage, as described by Kalbfleisch and Prentice (12). In all analyses, probability values less than 0.05 were regarded as significant.

\section{Results}

Table 1 shows the distribution of the carcinomas according to FIGO stage and age. The mean age of the patients in the three stages of disease was 53 years $(\mathrm{SD} \pm 12.9$ years) and ranged from 25 to 89 years. Of the 220 SCC, $21 \%$ were FIGO stage I, $28 \%$ stage II, and $51 \%$ stage III.

Positive immunostaining for c-myc protein was detected in $89(40 \%)$ cases, $29 \%$ being grade $1,9 \%$ grade 2 , and $2 \%$ grade 3 . The distribution of positive c-myc according to FIGO stage was $19 \%$ ( 17 women) in stage I, 33\% (29) in stage II, and 48\% (43) in stage III of disease.

Of the 220 women, only 116 completed the standard FIGO treatment within 120 days: $13.5 \%$ (30 women) were submitted to surgery alone, $8 \%(18)$ to surgery plus radiotherapy, $1.5 \%$ (3) to concomitant chemotherapy and radiotherapy, $16.5 \%$ (36) to external radiotherapy, and $13 \%$ (29) to radiotherapy plus brachytherapy. Twenty-one percent (46 women) completed treatment within a non-standard period of 150 to 365 days, and $26.5 \%$ (58 women) did not complete treatment because they interrupted it or died

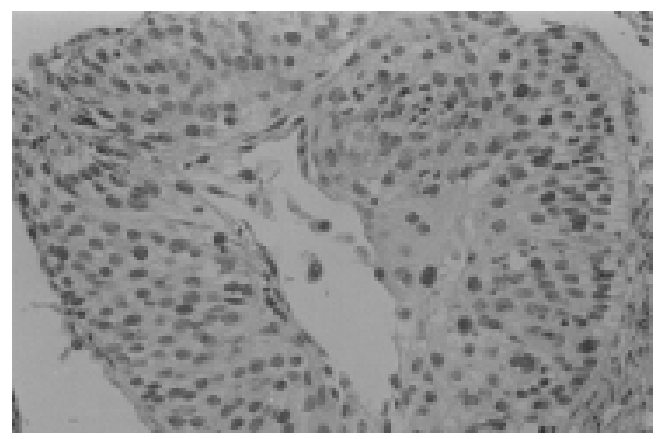

Table 1. Distribution of the patients with cervical squamous cell carcinoma according to FIGO stage and age.

\begin{tabular}{lccc}
\hline FIGO stage & N (\%) & \multicolumn{2}{c}{ Age (years) } \\
\cline { 3 - 4 } & & Mean \pm SD & Range \\
\hline I & $47(21)$ & $46 \pm 11.5$ & $28-74$ \\
II & $61(28)$ & $51 \pm 11.1$ & $32-73$ \\
III & $112(51)$ & $57 \pm 12.8$ & $25-89$ \\
Total & 220 & $53 \pm 12.9$ & $25-89$
\end{tabular}

Figure 1. Positive immunohistochemistry staining for c-myc demonstrating nuclear reactivity. Magnification 400X. 
of the disease during therapy. These patients were not considered in the survival analyses.

The effect of c-myc on disease-free survival was analyzed by univariate (KaplanMeier) survival analysis, including those 116 women who completed the standard FIGO treatment, and the survival curves for positive and negative c-myc protein were compared by the Wilcoxon test, adjusted by FIGO stage. During a period of 60 months, the disease-free survival was lower for women with c-myc-positive tumors, i.e., $60.5,47.5$ and $36.6 \%$ at 12,36 and 60 months of follow-up, respectively, but the difference was not statistically significant (Table 2). Multivariate (Cox) analysis was not appropriate because the assumption of proportional hazards was violated.

\section{Discussion}

Data on the prognostic significance of c-myc in cervical cancer are highly controversial, both confirmatory studies and those failing to show such an association being available. Accordingly, in a series of 93 women with stage Ib-IIb SCC, Northern blot and Slot blot hybridization techniques showed c-myc expression in $33 \%$ of the tumors (7). The frequency of c-myc increased in parallel to the tumor size, and multivariate analysis showed three factors associated with risk of relapse: tumor size, nodal status and c-myc protein. Furthermore, the women with c-myc had a 6.1 times higher risk of distant metastases at 3 years of follow-up (7). Simi-

Table 2. Disease-free survival (DFS) of cervical carcinoma patients stratified by FIGO stage and c-myc expression.

\begin{tabular}{lcccccccc}
\hline c-myc & Total & Relapse & \multicolumn{5}{c}{ DFS (\%) } & \multirow{2}{*}{$\mathrm{P}$} \\
\cline { 2 - 3 } \cline { 5 - 7 } & $\mathrm{N}$ & $\mathrm{N}$ & & 12 months & 36 months & 60 months & \\
\hline Negative & 67 & 30 & 67.3 & 54.1 & 46.9 & $0.67^{*}$ & $0.71^{* *}$ \\
Positive & 49 & 26 & & 60.5 & 47.5 & 36.6 & & \\
\hline
\end{tabular}

*Univariate Wilcoxon test.

$* *$ Wilcoxon test, adjusted by clinical stage. lar results were reported in another study in which immunohistochemical staining disclosed c-myc protein in $33 \%$ of the 48 patients (8). There was a higher risk of relapse, and the 5-year survival rate was significantly lower for these c-myc-positive women.

In contrast, there are studies that failed to show any prognostic association between c-myc protein and cervical cancer following treatment. Thus, in a series of 55 women with stage III-IV SCC, the frequency of c-myc expression was $45.1 \%$ and there was no association between c-myc protein, recurrence, metastases or survival at 3 years of follow-up (9). Another study included 66 women with stage Ib-IIa disease, and failed to establish any prognostic value for c-myc protein (10). Similar results were reported for 70 mainly stage II-III cervical cancer patients (13) and for 69 women with cervical SCC (14). The value of these two studies is limited by their small sample size, precluding meaningful statistical analysis.

The association of c-myc protein with cancer progression and a worse prognosis is incompletely understood, but could be explained in part by its role in cell cycle regulation. In mammalian cells, c-myc acts as an upstream regulator of cyclin-dependent kinases and functionally antagonizes the action of at least one cyclin-dependent kinase inhibitor, p27. Reduction of c-myc expression or its inappropriate expression can lead to cell death by apoptosis (4). Also, the transcription and processing of rRNA, and translation of ribosomal proteins seem to be regulated by c-myc (15).

Whatever the final role of c-myc in cervical carcinogenesis proves to be, it seems clear by now that there is no direct relationship between the detectable protein and the mutated gene. It could be anticipated that whenever the c-myc gene is mutated, the respective (altered) protein could be detected. That this is not the case was shown in a study in which c-myc protein was detectable in 57 cervical carcinomas and alterations in the 
exon 1 of the c-myc gene were analyzed in 40 of these cases. Interestingly, correlation between the detectable c-myc protein and mutations of the c-myc gene was observed in only $7.5 \%$ of these patients (16).

Despite the potential role of the c-myc gene and its protein as biological markers in human malignancies, the current data on cervical cancer are far from conclusive. This is due to multiple and not mutually exclusive reasons, e.g., the selection bias of the patient material. The present study was carried out on Brazilian women who had not been routinely screened for cervical cancer because of many cultural and social problems limiting their access to the Papanicolaou smear (17). Thus, the invasive disease developed without any diagnostic (or therapeutic) interventions until the time of diagnosis. Consequently, $51 \%$ of these women were diagnosed as stage III disease with bulky tumors and severe clinical complications. Survival analyses could be performed for 116/220 women only, i.e., for those who had completed the standard FIGO treatment within
120 days.

In the present study, the effect of c-myc on disease-free survival could be analyzed by univariate (Kaplan-Meier) survival analysis only, and including those 116 women who completed the standard FIGO treatment. Although there was a trend towards lower disease-free survival rates at 12,36 , and 60 months of follow-up for c-myc-positive tumors, the survival curves for c-mycpositive and -negative cases (Wilcoxon test) were not significantly different when adjusted by FIGO stage. Because the assumption of proportional hazards was violated, unfortunately Cox multivariate survival analysis was not appropriate.

Although the present data suggest that immunohistochemical demonstration of c-myc does not possess any prognostic value independent of FIGO stage, and as such is unlikely to be a useful prognostic marker in cervical SCC, confirmation of this observation by additional prospective cohort studies and multivariate analyses is warranted.

\section{References}

1. Armelin HA, Armelin MCS \& Kovary K (1988). Neoplastic transformation of 3T3 mouse embryo cells with c-myc and c-Haras-1 oncogenes. Brazilian J ournal of Medical and Biological Research, 21: 1155-1161.

2. Manolov G \& Manolova $Y$ (1972). Marker band in one chromosome 14 from Burkitt lymphomas. Nature, 237: 33-34.

3. Godwin AK, Schultz DC, Hamilton TC \& Knudson-J r AG (1997). Oncogenes and tumor suppressor genes. In: Hoskins WJ , Perez CA \& Young RC (Editors), Principles and Practice of Gynecology Oncology. 2nd edn. Lippincott-Raven Publishers, Philadelphia, PA, USA, 107-148.

4. Steiner $P$, Rudolph B, Muller D \& Eilers M (1996). The functions of myc in cell cycle progression and apoptosis. Progress in Cell Cycle Research, 2: 73-82.

5. Couturier J, Sastre-Garau X, SchneiderMaunoury S, Labib A \& Orth G (1991). Integration of papillomavirus DNA near c-myc genes in genital carcinomas and its consequences for proto-oncogene expression. J ournal of Virology, 65: 45344538.

6. Cho KR (1998). Cervical cancer. In: Vogelstein B \& Kinzler KW (Editors), The Genetic Basis of Human Cancer. McGrawHill, New York, NY, USA.

7. Bourhis J, Le MG, Barrois M, Gerbaulet A, J eannel D, Duvillard P, Le Doussal V, Chassagne D \& Riou G (1990). Prognostic value of c-myc proto-oncogene overexpression in early invasive carcinoma of the cervix. J ournal of Clinical Oncology, 8: 1789-1796.

8. Wu HJ (1996). The expression of c-myc protein in uterine cervical cancer: a possible prognostic indicator. Nippon Sanka Fujinka Gakkai Zasshi, 48: 515-521.

9. Symonds RP, Habeshaw T, Paul J, Kerr DJ , Darling A, Burnett RA, Sotsiou F, Linardopoulos S \& Spandidos DA (1992). No correlation between ras, c-myc and c-jun proto-oncogene expression and prognosis in advanced carcinoma of cervix. European J ournal of Cancer, 28: 16151617.

10. Brewer CA, Liao SY, Wilczynski SP, Pastorekova S, Pastorek J, Zavada J , Kurosaki T, Manetta A, Berman ML, DiSaia P \& Stanbridge EJ (1996). A study of biomarkers in cervical carcinoma and clinical correlation of the novel biomarker MN. Gynecologic Oncology, 63: 337-344.

11. MacLean CD (1996). Principles of cancer screening. Medical Clinics of North America, 80: 1-14.

12. Kalbfleisch J D \& Prentice RL (1980). The Statistical Analysis of Failure Time Data. J ohn Wiley and Sons, New York, NY, USA, 336.

13. Dellas A, Schultheiss E, Leivas MR, Moch $H \&$ Torhorst J (1998). Association of p27Kip1, cyclin E and c-myc expression with progression and prognosis in HPVpositive cervical neoplasms. Anticancer 
Research, 18: 3991-3998.

14. Polischouk AG, Scotnikova OI, Sergeeva NS, Zharinov GM, Lewensohn R \& Zhivotovsky B (1997). Response to radiotherapy of human uterine cervix carcino$\mathrm{ma}$ is not correlated with rearrangements of the Ha-ras or c-myc genes. European J ournal of Cancer, 33: 942-949.
15. Schmidt EV (1999). The role of c-myc in cellular growth control. Oncogene, 18: 2988-2996.

16. O'Leary J J, Landers RJ , Crowley M, Healy I, Kealy WF, Hogan J \& Doyle CT (1997). Alterations in exon 1 of c-myc and expression of p62 c-myc in cervical squamous cell carcinoma. J ournal of Clinical Patholo- gy, 50: 896-903.

17. Brenna SMF, Hardy E, Zeferino LC \& Uemura I (2001). Conhecimento, atitude e prática do exame de Papanicolaou em mulheres com patologia cenvical. Cadernos de Saúde Pública, 17: 909-914. 